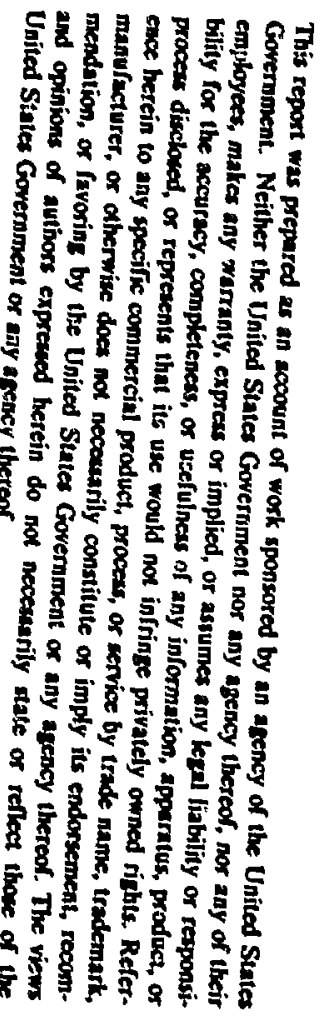

Distribution Category: Magnetic Fusion Energy (UC-20)

ANL/FPP/TM-209

ANL/FPP/TM--209

DE87 008076

\section{SIZE LIMTATIONS POR EICRONAVB GAVITY TO SIFULATB GEATIMG OP DLANRET MATERIAL IA EUSIOA REACTOR}

by

David Wolf*

January 1987

*Work supported by the U. S. Department of Energy/Office of Fusion Energy under Contract No. "W-31-109-ENG-38. 
Page

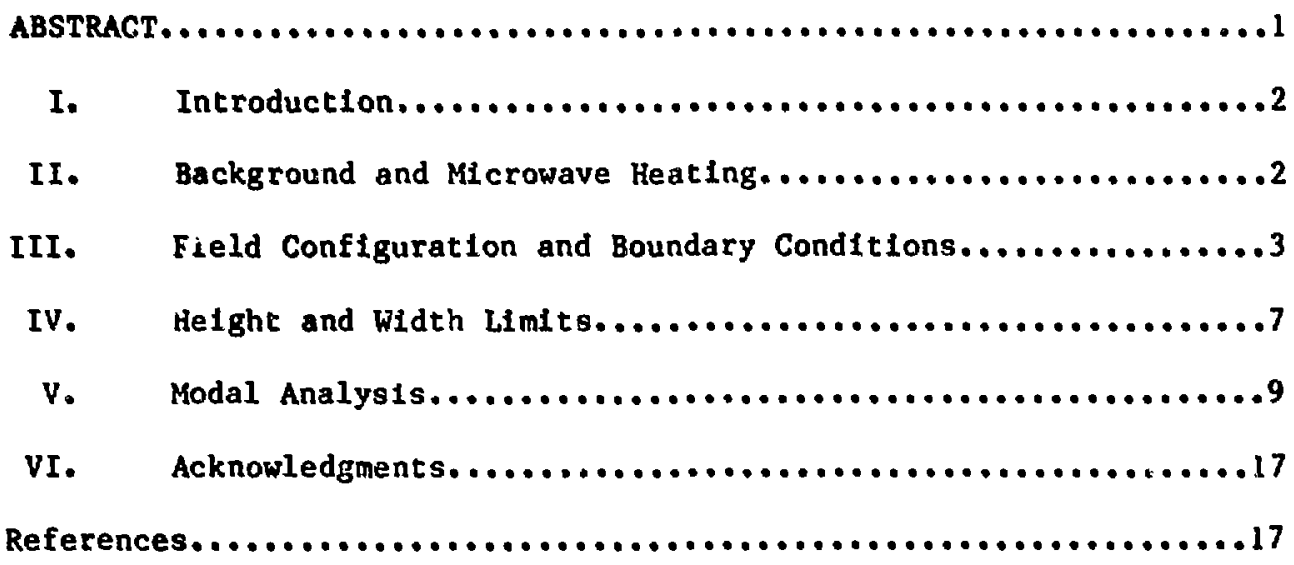


1. Geometry of Blanket Material Sample in Cavity..............4

2. Comparison Between Exponent1al and Jine-Squared Functions....8

3. Sample Section and Matching Section...................10

4. Plot of Electric Field at $2=0$ Interface, $a=0.17 \ldots \ldots \ldots .15$

5. Plot of Electric Fleld at $z=0$ Interface with $a=0.19 \ldots \ldots 16$

\section{LIST OE TABLES}

Nuaber

Page

1. $k_{1 n}$ and $k_{2 n}$ for $a . .361$ m......................1

2. Coefficients of Modes for a $\ldots .361$ m..................... 


\title{
SIZE LIMITATIONS FOR MIGRONAVE CAVITY TO SIMULATE IEATIMG OF BLANKET MATERIAL IN FUSION REACTOR
}

by

David Wolf

\begin{abstract}
The power profile in the blanket materlal of a nuclear fuston reactor can be simulated by using microwaves at $200 \mathrm{MHz}$. Using these microwaves, ceramic breeder materials can be thermally tested to determine their acceptability as blanket materials without entering a nulcear fuslon environment. A resonating cavity design is employed which can achieve uniform cross sectional heating in the plane transverse to the neutron flux. As the sample size increases in helght and width, higher order modes, above the dominant mode, are propagated and destroy the approximation to the heating produced in a fuston reactor. The 11 mits at which these modes develop are determined in the paper.
\end{abstract}




\section{INmODOCTION}

In nuclear fusion reactor, the blanket section is subjected to a neutron flux produced by the fusion of deuterium and tritium atoms in the plasma. By selectiris a proper material, in this case a lithium compound ( $r-$ $\left.\mathrm{LiAlO}_{2}\right)$, these neutrons react with the blanket material and breed more tritium fuel by the reaction

$$
\mathrm{O}^{\mathrm{n}^{2}}+3^{\mathrm{Li}}+2^{\mathrm{He}}+1^{\mathrm{H}^{3}} \cdot
$$

The blanket also converts the kinetic energy of the escaping neutrons into heat, which is then transferred to a coolant and eventually to a generator to produce electricity.

The heating of the blanket material in the fusion reactor is related to the power $10 s 8$ in the material. In the reactor, the power profile (volumetric power 1089 ) is 2

$$
P(z)=P_{0} e^{-q z}
$$

where

$$
\begin{aligned}
P_{0} & =2.4 \times 10^{7} \mathrm{w} / \mathrm{m}^{3} \\
q & =8.8 \mathrm{~m}^{-1} \\
z & =\text { blanket depth. }
\end{aligned}
$$

As can be seen from the above equation, the power $108 \mathrm{~s}$ is independent of both $x$ and $y$ and is thus uniform across these cross sections.

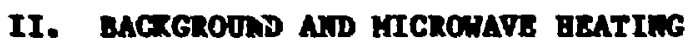

For lossy materials, the dielectric constant is composed of real and imaginary parts. It is the imaginary part that enters into the volumetric power 2088 in the equation ${ }^{3}$

$$
P(z)=\frac{1}{2^{\omega}} \varepsilon_{\text {im }} \varepsilon_{0} E(z)^{2}
$$

where 


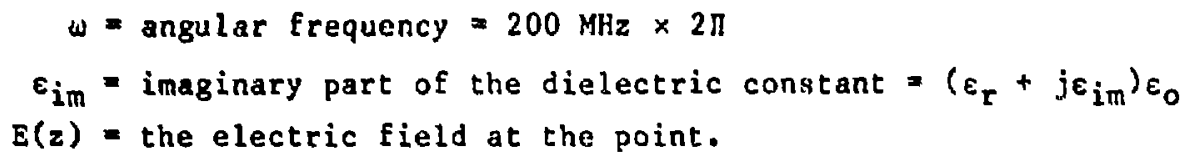

For the material chosen, $Y-\mathrm{LiAlO}_{2}, \varepsilon_{Y}=2.87$ and $\varepsilon_{\mathrm{i} \text { m }}=.01$. In deriving the field configurations, $\varepsilon_{i m}$ may be neglected since it is much smaller then $\varepsilon_{r}$.

In the cavity design, the blanket material sample in $F i g .1$ is bordered on two sides by another dielectric, on the bottom, top, and front by copper walls, and the back face is matched to a loading cavity. Although copper is not a perfect conductor, it is sufficient to approximate it as such, since the power loss in the copper walls is much less than that in the blanket section.

\section{FIELD COMTIGURATION AND BOUNDARY CONDITIONS}

To find the electric field, Maxwell's equations and the scaler Helmholtz equation are used. 4 The magnetic field is then given by

$$
\vec{\nabla} \times \vec{E}=\mathrm{j} \omega \mu \vec{H}
$$

assuming an $\mathrm{e}^{\mathrm{j \omega t}}$ time dependence.

Boundary conditions imposed by the conducting walls force the tangential electric field to be zero at the walls. In the blanket section we desire a TE mode. 5 This will result in an electric field that only has a $y$ component and is zero only at the side walls. Solving Maxwell's equations urider these constraints leads to a general solution for the field in the blanket section

$$
E_{y}=E_{0} \cos \left(k_{x} x\right) \cos \left(k_{y} y\right) \sin \left(k_{z}(l-z)\right)
$$

where $l$ is the $z$ coordinate of the front wall and $k_{x}, k_{y}$, and $k_{z}$ have yet to be determined. As apparent, this equation is not independent of $x$ and $y$ and will thus not accurately approximate the power profile we desire. In order to eliminate the $y$ dependence, we must: set $k_{y}=0$. Since $k_{y}=m \pi / d(m=0,1,2 \ldots)$, this requires that we allow only $T E_{n o}$ modes to propagate. To achieve this, we must restrict the height of the cavity, thus the value of $d$, such that the $m=$ 1 mode is not propagated. To begin with, a value of $0.10 \mathrm{~m}$ is used. 


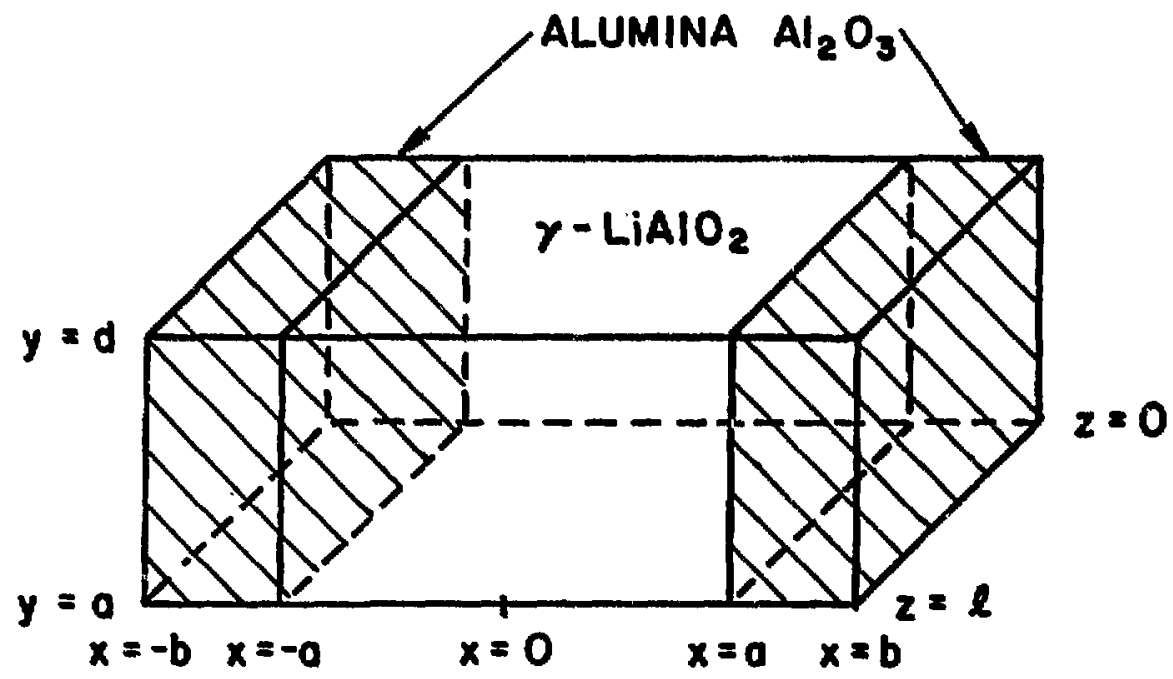

Fig. 1 Geometry of Blanket Material Sample in Cavity 
We cannot eliminate the $x$ dependence in a similar manner, for if $k_{x}=0$ and $E_{y}$ must equal zero at the side walls, then there could not be $a$ field in the cavity. To circumvent this problem, the second material is placed between the lithium sample and the side walls (see Fig. 1). The electric field then bccomes

$$
\begin{aligned}
E_{y} & =c_{2} \cos \left(k_{2} x\right) \sin \left(k_{z}(l-z)\right) & |x|<a \\
& =c_{1} \sin \left(k_{1}(x-b)\right) \sin \left(k_{z}(l-z)\right) & a<|x|<b
\end{aligned}
$$

and the uniform heating of the sample is obtained by setting $k_{2}=0$.

The fields must be continuous across the boundaries $x=-a$ and $x=a$, Continuity of $\vec{E}$ fields leads to

$$
c_{2} \cos \left(k_{2} a\right) \sin \left(k_{z}(l-z)\right)=c_{1} \sin \left(k_{1}(a-b)\right) \sin \left(k_{z}(l-z)\right)
$$

Continuity of fields is related to the derivatives of the fields. We need only examine $\partial \vec{E} / \partial x$ since the other derivatives are satisfied when $\mathrm{Eq} \cdot$ [4] is. Continuity of $\partial \vec{B} / \partial x$ yields

$$
-c_{2} k_{2} \sin \left(k_{2} a\right) \sin \left(k_{2}(l-z)\right)=c_{1} k_{1} \cos \left(k_{1}(a-b) \sin \right)\left(k_{2}(l-z)\right) \text {. }
$$

Combining Eqs. [4] and [5]

$$
-k_{2} \tan \left(k_{2} a\right)=k_{1} \cot \left(k_{1}(a-b)\right)
$$

The scaler Helmholtz equation, $\nabla^{2} \underline{E}+\omega^{2} E \mu^{t}=0$, must also be satisfied. Applying this to Eq. [3] yields

$$
\begin{aligned}
& -k_{2}^{2}-k_{2}^{2}+\omega^{2} \varepsilon_{2} \varepsilon_{0} \mu=0 \\
& -k_{1}^{2}-k_{2}^{2}+\omega^{2} \varepsilon_{1} \varepsilon_{0} \mu=0
\end{aligned}
$$

where

$$
\varepsilon_{2}=2.87 \text {, relative dielectric constant for } \gamma-\mathrm{LiAlO}_{2}
$$


$\varepsilon_{1}=8.5$, relative dielectric constant for alumina, $\mathrm{Al}_{2} \mathrm{O}_{3}$

$\mu=4 \pi \times 10^{-7}$ Henry $/ \mathrm{m}$, permeability of free space.

Equations [6], [7], and [8] give us three equations in three unknowns that must be solved numerically. However, as mentioned earlier, we desire $k_{2}=$ 0 . If this is so, then Eq. [6] reduces to

$$
k_{1}(a-b)=\left(n+\frac{1}{2}\right) \pi \quad(n=\ldots,-1,0,1, \ldots)
$$

and eliminating $k_{z}$ from Eqs. [7] and [8]

$$
k_{1}^{2}-k_{2}^{2}=\omega^{2}\left(\varepsilon_{1}-\varepsilon_{2}\right) \varepsilon_{0}^{\mu}
$$

or

$$
k_{1}-\sqrt{\omega^{2}\left(\varepsilon_{1}-\varepsilon_{1}^{E}{ }_{0}^{\mu}\right.}=9.94 \mathrm{~m}^{1}
$$

Using this value for $k_{1}$ in Eq. [9] and solving for the smallest value for (ab),

$$
(b-a)=\frac{\pi}{2 k_{1}}=0.15797 \mathrm{~m}
$$

Therefore, as long as the width of the alumina on the sides of the lithium sample is fixed at $.15797 \mathrm{~m}$, then $k_{2}=0$ is an acceptable solution to the equations and we have achieved the uniformity of the power 1088 across the sample.

Although we have successfully simulated the uniform heating of the sample, the electric field now varies sinusoidally with $z$. Therefore, from Eq. [2], the power profile is now proportional to $\sin ^{2}\left(k_{z}(l-z)\right)$ instead of the actual power profile in Eq. [1]. In order to match the sine-squared function to the exponential function of Eq. [1], we look for the point, $z_{0}$, where the functions and their first derivatives match. Setting the functions equal,

$$
A \sin ^{2}\left(k_{2}\left(l-z_{0}\right)\right)=B e^{-q z_{0}}
$$

where $A$ and $B$ are arbitrary amplitudes. Setting the derivatives equal, 


$$
-2 A k_{2} \sin \left(k_{2}\left(l-z_{0}\right)\right) \cos \left(k_{2}\left(l-z_{0}\right)\right)=-B q e^{-q 2} 0
$$

Substituting Eq. [12] into Eq. [13] and solving for $\left(l-z_{0}\right)$,

$$
\left(l-z_{0}\right)=\frac{1}{k_{z}} \tan ^{-1}\left(\frac{2 k_{z}}{q}\right) \text {. }
$$

We can solve for $k_{2}$ from Eq. [8] with $k_{2}=0$, giving

$$
k_{2}=\sqrt{\omega^{2} \varepsilon_{2} \varepsilon_{0} \mu}=7.099 \mathrm{~m}^{-1}
$$

Evaluating Eq. [14] now given

$$
\left(l-z_{0}\right)=.143 \mathrm{~m}
$$

Therefore, the blanket section is to be built with a depth of $.173 \mathrm{~m}(.143$ for the optimal point plus another .03 for region of interest) with $k-.173, z_{0}=$ $.03 \mathrm{~m}$. The magnitude of $B$ is chosen 80 that at $\varepsilon=$ ), the power $108 \mathrm{~s}$ is 24 W/cc. A is then found from Eq. [12] with $\Sigma_{0}=.03$, giving $A=25.53 \mathrm{w} / \mathrm{cc}$. These two functions are graphed in Fig. 2. Over the first six centimeters of the blanket section, the graphs are within $7 \%$ of each other.

\section{I7. HBIGAT AND WIDTH LIMITS}

Operating at $200 \mathrm{kHz}$ and with a sample section of $.1 \mathrm{macross}$, only the first mode, the one with $k_{2}=0$, is allowed to propagate. However, as the width of the sample section increases, higher modes for which $k_{2}$ does not equal zero are also propagated and thus disrupt the uniformity in the $x$ and $y$ directions. By solving the equations for the next values of $k_{1}, k_{2}$, and $a$, we are able to determine the maximum width of the cavity. If we keep the dimension of $(b-a)$ at .15797 , the dowinant node in the alumina is the first one. As we allow a to increase, different values of $k_{1}$ and $k_{2}$ are found using Eq. [6]. By setting $k_{z}=0$, we can find the cutoff frequencies for the first two modes. As the width of the cavity increases, the cutoff frequencies of the modes decreass, until at $a=.362 \mathrm{~m}$, the cutoff frequency of the second 


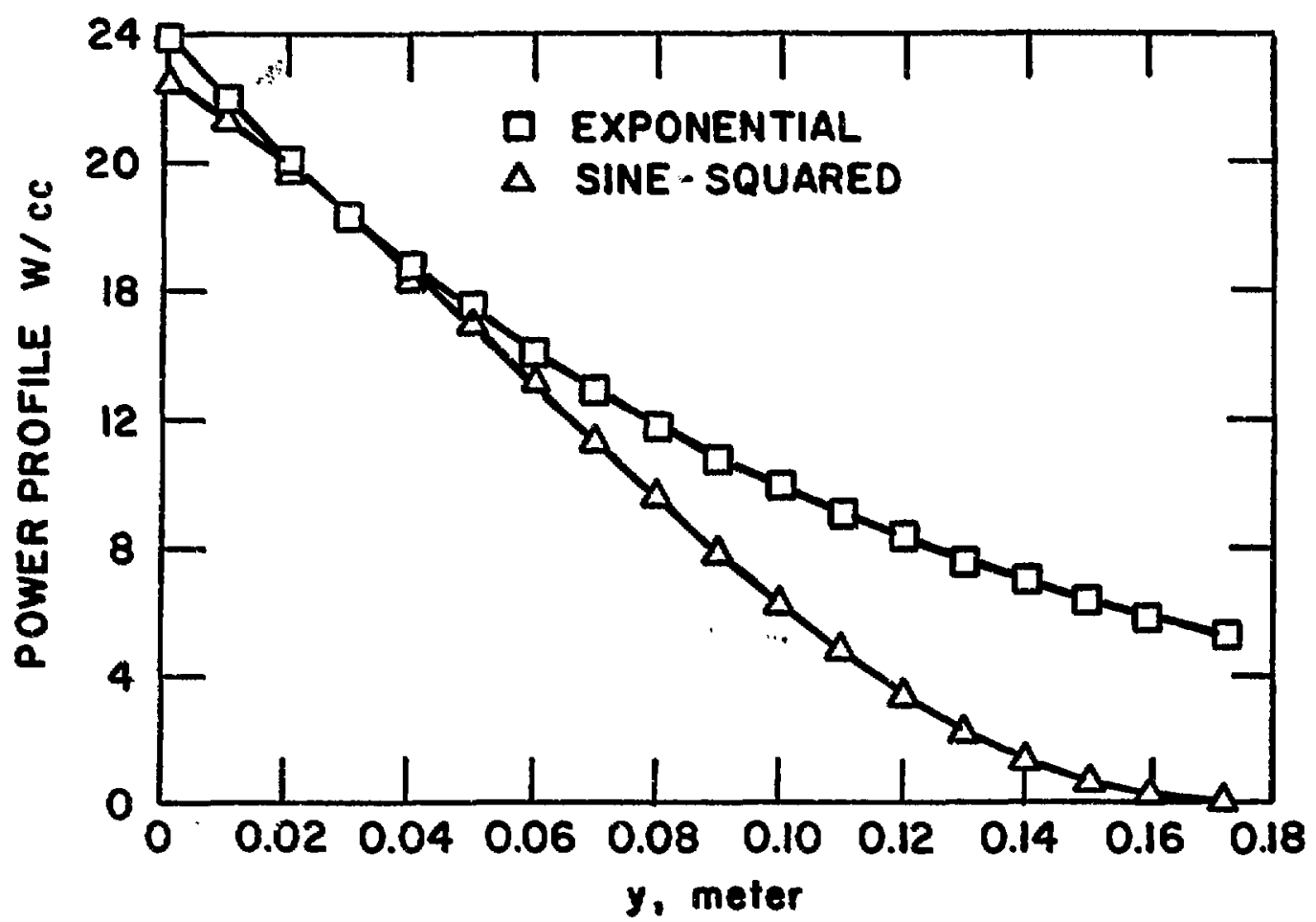

Fig. 2 Comparison between Exponential and Sine-Squared Functions 
mode is less than $200 \mathrm{MHE}$. Therefore, in order to ensure that the second mode does not propagate and interfere with the first, the width of the blanket section muat be kept below $.722 \mathrm{~m}$.

To determine the maximum height of the cavity, we again look for the largest dimension in the $y$ direction before the second mode is propagated. Ao we saw earlier, the general solution to Maxwell's equations involves a $\cos \left(k_{y} y\right)$ term, where $k_{y}=m \pi / d(m=0,1,2 \ldots)$. Up to this point, we have been only considering the $n=0$ mode. Now we mut solve slightly different equations. Eqs. [7] and [8] become

$$
-k_{2}^{2}-k_{y}^{2}-k_{z}^{2}+\omega^{2} \varepsilon_{2} \varepsilon_{0} \mu=0
$$

and

$$
-k_{1}^{2}-k_{y}^{2}-k_{z}^{2}+\omega^{2} \varepsilon_{1} \varepsilon_{0} \mu=0
$$

respectively. Once again we mat find the oet of $k_{1}, k_{2}$, and d that oatisfy these two equations along with Eq. [6]. Doing this, we find that the smallest value for $d$ is $.442 \mathrm{~m}$. When $d$ is greater than this, the $m=1$ mode is propagated along with the $m=0$ mode, and the uniformity of the cavity heating is destroyed.

\section{v. modal anLISIS}

The design of Fig. I murt be linked to a matching section to complete the cavity. One type is shown in Fig. 3. At the interface between the matching section and the blanket section, higher order modes are generated to satisfy the continuity conditions discussed earlier. These modes way be tolerated if their magnitudes are sufficiently small and if they do not interfere greatly with the uniform heating of the sample. In the matching section, the dominant term of the electric field is

$$
E_{y}=A_{0} \cos \left(r_{0} x\right) \sin \left(r_{z 0}\left(z_{1}+z\right)\right)
$$

where $z_{1}$ is the coordinate of the back wall. With the discontinuity of media, the higher modes generated cause the electric fields on both sides of the interface to becone infinite sums. In the matching section, the fieid is 


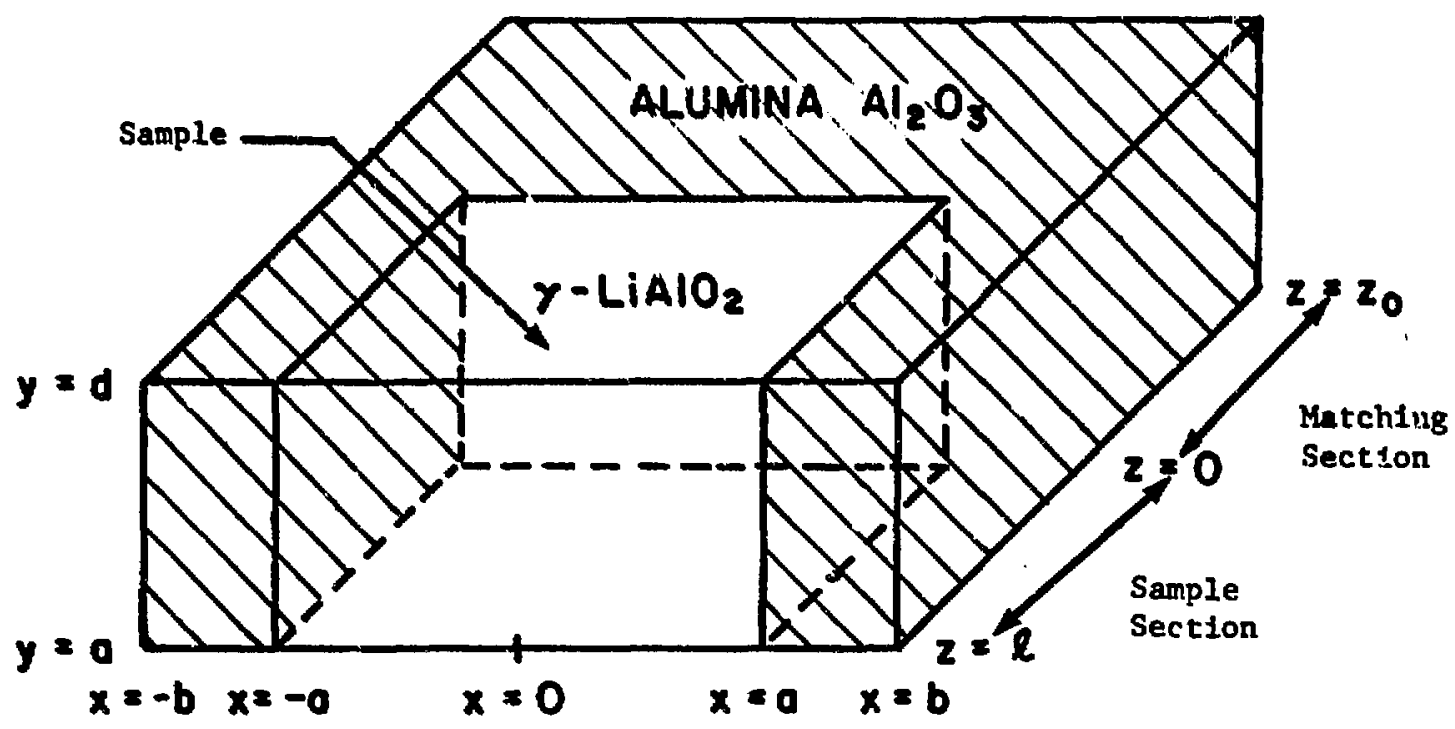

FIg. 3 Sample Section and Matching Section 


$$
z_{y}=\sum_{m=0}^{\infty} A_{m} \cos \left(r_{m} x\right) \sin \left(r_{z m}\left(z_{1}+z\right)\right)
$$

where

$$
r_{m}=\left(m+\frac{1}{2}\right) \pi / b \quad(m=0,1,2 \ldots)
$$

In the blanket section, for which $z>0$, the field becomes

$$
\begin{aligned}
E_{y} & =\sum_{n=0}^{\infty} C_{2 n} \cos \left(k_{2 n} x\right) \sin \left(k z_{z n}(l-z)\right) & |x|<a \\
& =\sum_{n=0}^{\infty} c_{1 n} \sin \left(k k_{1 n}(x-b)\right) \sin \left(k_{z n}(l-z)\right) & a<|x|<b
\end{aligned}
$$

$k_{1 n}$ and $k_{2 n}$ must be found numerically from Eqs. [6], [7], and [8], with the first five solutions given in Table 1.

$$
k_{1 n} \text { and } k_{2 n} \text { for } 1 .
$$
$\mathbf{n}$
$k_{\ln }\left(\right.$ in $\left.m^{-1}\right)$
$k_{2 n}\left(\right.$ in $\left.m^{-1}\right)$

0
1
2
3
4

9.9435

0.0000

12.2335

7.1104

17.1987

14.0328

22.8498

20.5730

28.5603

26.7735

Using Eq. [7], $r_{z m}$ and $k_{z n}$ can be found and are

$$
r_{2 \pi}=\gamma \omega^{2} \varepsilon_{m} \varepsilon_{0} \mu-r_{m}^{2}
$$




$$
k_{z n}=\sqrt{\omega^{2} \varepsilon_{1} \varepsilon_{0}^{\mu-k_{1 n}^{2}}}
$$

where $\varepsilon_{\mathrm{m}}$ - the relative dielectric constant of the matching section, here chosen to be that of alumina, 8.5. Note that if either $r_{z m}$ or $k_{z n}$ is imaginary, then $B \operatorname{ain}(j x)=j B \sinh (x)$, which is a valid expression for the siald. The value of $z_{1}$ can now be determined, $z_{1}$ is chosen so that at $z=0$, the first modes and their derivatives match. This requires that

$$
A_{0} \operatorname{in}\left(r_{20} z_{1}\right)=c_{20} \operatorname{in}\left(k_{20} l\right)
$$

and

$$
A_{0} r_{20} \cos \left(r_{20} z_{1}\right)=-c_{20} \cos \left(k_{20} l\right)
$$

Combining these and solving for $z_{1}$,

$$
z_{1}-\frac{1}{r_{20}} \tan ^{-1}\left(\frac{-r_{20}}{k_{20}} \tan \left(k_{20} l\right)\right) .
$$

For $a=.361$, Eq. [19] gives $z_{1}=.1505 \mathrm{~m}$.

As before, $\vec{E}$ and $\vec{E}$ must be continuous across the boundary, $z=0$. Setting the fields equal yields

$$
\begin{aligned}
\sum_{m=0}^{\infty} A_{m} \cos \left(r_{m} x\right) \sin \left(r_{2 m}{ }_{1}\right) & =\sum_{n=0}^{\infty} c_{2 n} \cos \left(k_{2 t i} x\right) \sin \left(k_{2 n} \ell\right) & |x|<a \\
\vdots & & \\
& =\sum_{n=0}^{\infty} C_{1 n} \sin \left(k_{\ln }(x-b)\right) \sin \left(k_{2 n} \ell\right) & a<|x|<b
\end{aligned}
$$

Using the orthogonality of $\cos \left(r_{m} x\right)$, we multiply both sides by $\cos \left(r_{m} x\right)$ and integrate from $-b$ to $b$ giving 


$$
\begin{aligned}
A_{m} \sin \left(r_{2 m} z_{1}\right) & =\sum_{n=0}^{\infty} \frac{1}{b} \sin \left(k_{2 n} l\right)\left[2 \int_{0}^{a} c_{2 n} \cos \left(k_{2 n} x\right) \cos \left(r_{m} x\right) d x\right. \\
& \left.+2 \int_{a}^{b} c_{1 n} \sin \left(k_{1 n}(x-b)\right) \cos \left(r_{m} x\right) d x\right] .
\end{aligned}
$$

Using Eqs. [4] and [5] to find $c_{1 n}$ in terms of $C_{2 n}$, and performing the above integration leads to

$$
\begin{gathered}
A_{m} \sin \left(r_{z: n} z_{1}\right)=\sum_{n=0}^{\infty} \frac{2 C_{2 n} \sin \left(k_{z n} l\right)}{b}\left(\frac{1}{k_{1 n}^{2}-r_{n}^{2}}-\frac{1}{\left.k_{2 n}^{2}-r_{m}^{2}\right)}\right) \\
\quad \times r_{m} \sin \left(r_{m} a\right) \cos \left(k_{2 n} a\right)-k_{2 n} \sin \left(k_{2 n} a\right) \cos \left(r_{m} a\right)
\end{gathered}
$$

$\nabla_{E}$ must also be continuous across the boundary. Taking the $z$ derivative of Eqs. [17] and [18] and equating them gives

$$
\begin{aligned}
& \sum_{m=0}^{\infty} A_{m} r_{2 m} \cos \left(\varepsilon_{m} x\right) \cos \left(r_{2 m}{ }^{2}\right)=\sum_{n=0}^{\infty}-C_{2 n}{ }^{k}{ }_{2 n} \cos \left(k_{2 n} x\right) \cos \left(k_{2 n}^{l}\right) \quad|x|<a \\
& =\sum_{n=0}^{\infty}-c_{1 n} k_{2 n} \sin \left(k_{1 n}(x-b)\right) \cos \left(k_{2 n}^{l} l\right) \quad a<|x|<b
\end{aligned}
$$

Multiplying by $\cos \left(r_{\mathfrak{m}} x\right)$ and integrating as before, Eq. [23] becomes

$$
\begin{aligned}
& A_{m^{2}}{ }_{2 m} \cos \left(x_{2 m^{2}}{ }_{1}\right)=\sum_{n=0}^{\infty} \frac{-C_{2 n^{k} 2 n} \cos \left(k 2 n^{2}\right)}{b}\left(\frac{1}{k_{1 n}^{2}-r_{m}^{2}}-\frac{1}{k_{2 n}^{2}-r_{m}^{2}}\right) \\
& \times\left(r_{m} \operatorname{gin}\left(r_{m} a\right) \cos \left(k_{2 n} a\right)-k_{2 n} \sin \left(k_{2 n}^{a}\right) \cos \left(r_{m}^{a} a\right)\right.
\end{aligned}
$$


Setting $A_{0}-1$, we can solve the infinite set of equations in [22] and [24] using a matrix of the truncated set of equations and thus determine the coefficients of the firat several modes. 6 These are given in Table 2.

TABLE 2.

Coefficients of Modes for $a=.361 \mathrm{~m}$.

\begin{tabular}{ccc}
\hline $\mathbf{n}$ & $C_{2 n}$ & $A_{n}$ \\
\hline 0 & 0.8588 & 1.000 \\
1 & 2.6918 & -0.5546 \\
3 & 0.0521 & -0.0310 \\
\hline
\end{tabular}

As can be seen from the table, the dominant mode in the cevity is not the firat one, for which $k_{2}-0$, rather it is the second mode. Therefore, the power loss will not be uniform across the blanket material. As the value of a decreases, the coefficient of the first mode increases, and that of the second mode decreases, since the region of desired flatness decreases and the field becomes closer to the dominant cosine wave in the matching section,

By performing the above modal analysis for varying values of $a$, we find that for $a=.17$, the variation of $E$ across the lithiun sample is less than 107. If a increases to .19, the variation becomes approximately 20\%. From Eq. [2] we can find the magnitude of the electric field needed at the interface,

$$
E(0)=\left(\frac{2 P_{0}}{\omega \varepsilon_{i m} \varepsilon_{0}} H_{/ 2}=0.656 \mathrm{NV} / \mathrm{m} .\right.
$$

Taking this value for $A_{0}$, we can plot the approximate electric field at $z=$ 0 . This is shown in Fig. 4 for $a=.17$ and in Fig. 5 for $a=.19$.

In order to keep the heating of the lithium sample to within $10 \%$ of being uniform, the largest blanket section that can be used for this type of section experiment is $17 \mathrm{~cm} \times 44.2 \mathrm{~cm} \times 17.3 \mathrm{~cm}$. This blanket section is bordered on the sides by a section of alumina that is $15.797 \mathrm{~cm}$ wide, and is attached to a matching section of more alumina that is $15.96 \mathrm{~cm}$ deep. The exponential decay 


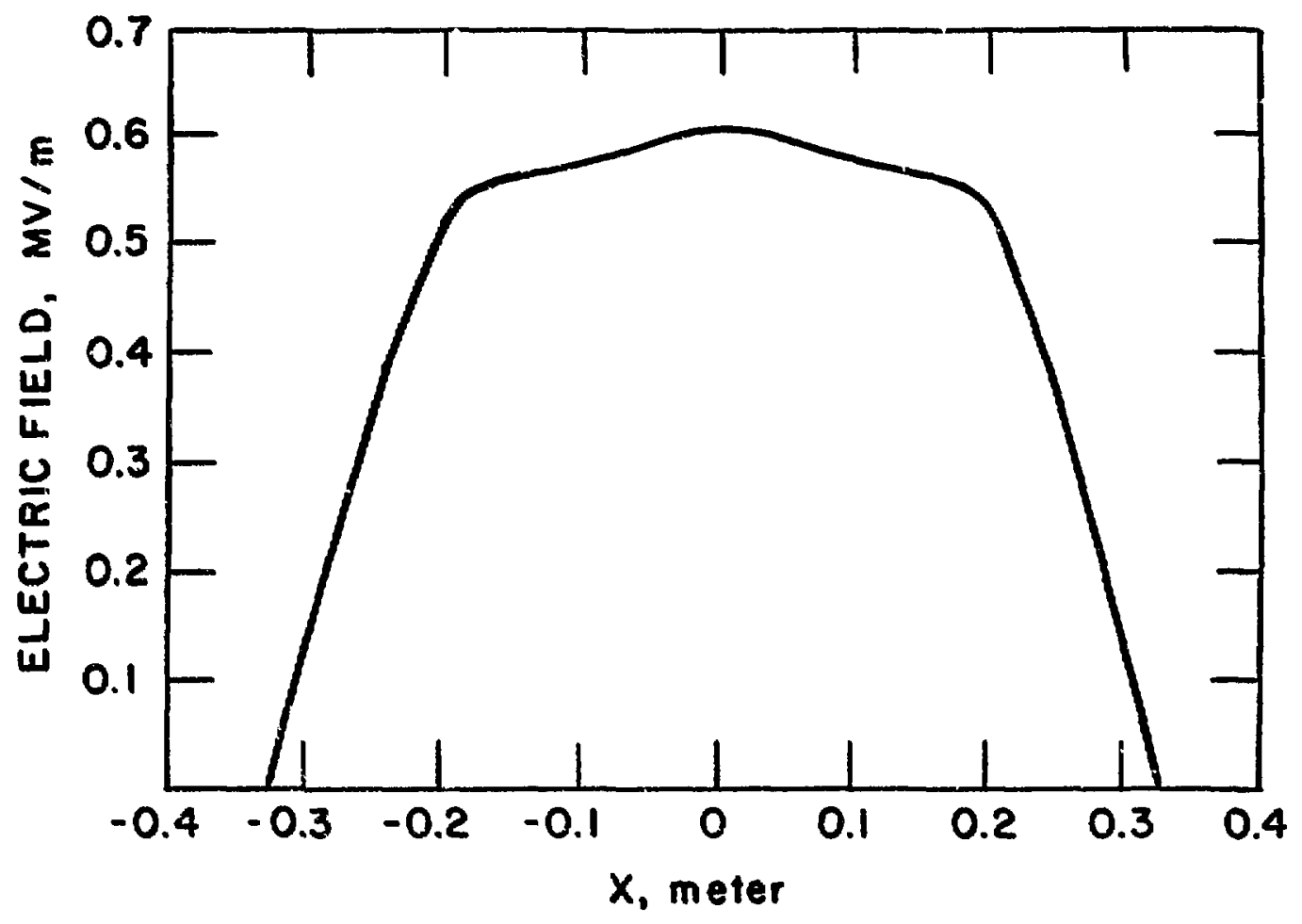

Fig. 4 Plot of Electric Field at $2=0$ Interface, $a=0.17$ 


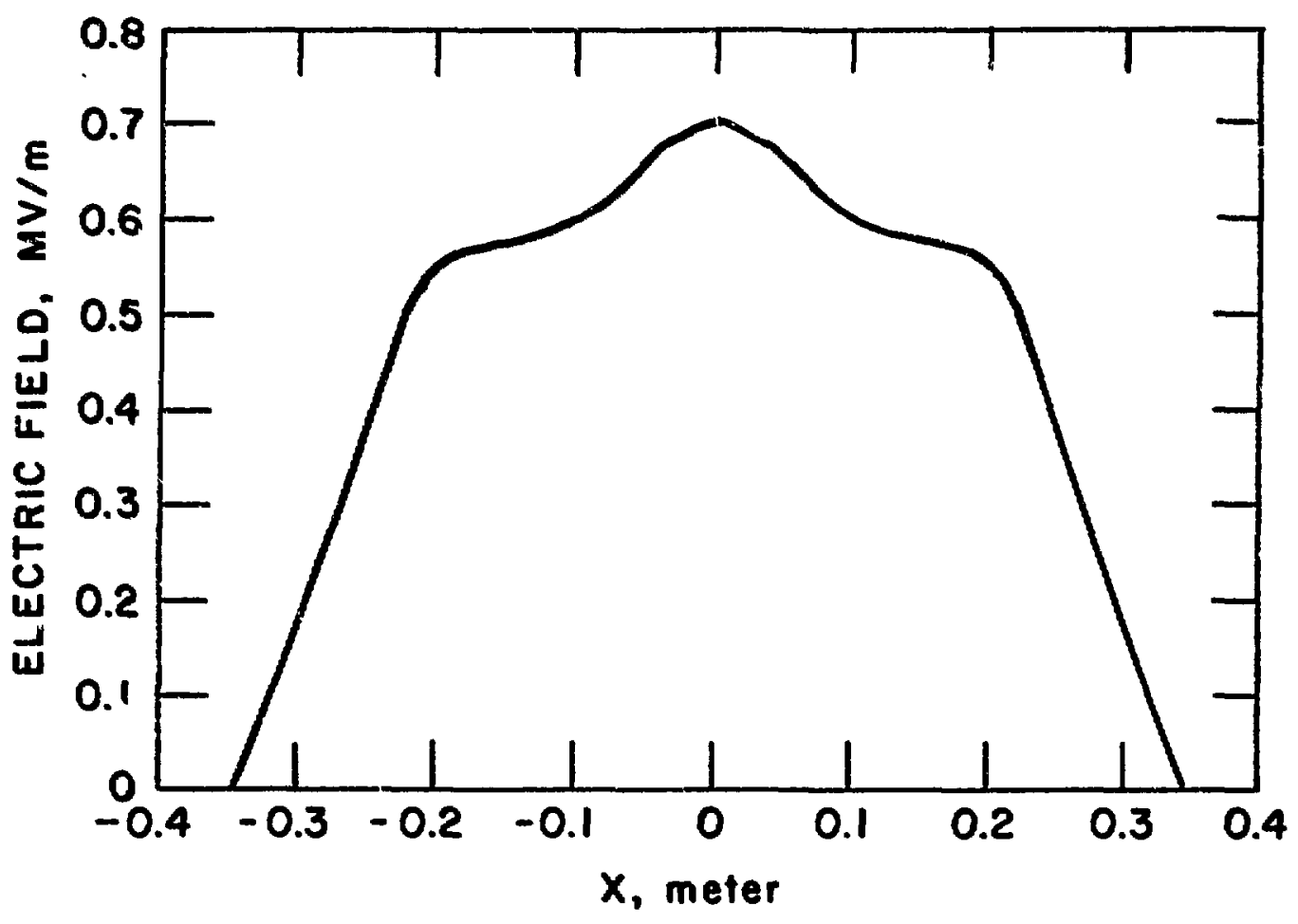

8ig. 5 Plot of Electric Field at $Z=0$ Interface with $=0.19$ 
in the $z$ direction has been approximated by a sine-squared, with the first six centimeters being a close match.

\section{HCKHOWLBDEIBNTS}

I would like to thank Dr. Robert Kustom for providing the topic for this profect, offering his guidance, and answering my innumerable questions. I would also like to thank Joug Couwenhoven, my colleague, for assisting me with this project.

\section{VII.REFERENGES}

1. Fendley, Paul, "Waveguide and Cavity Designs to Reproduce a Fusion Reactor Blanket Material Power Profile," Argonne Summer Research Participant, 1984.

2. Kustom, R. L., et al., "Design of the Waveguide for Microwave Heating of Solid Lithium Ceramic Blankets," ANL/EPP/TM.198, Argonne National Laboratory, 1985.

3. Harrington, Roger, Time-Harmonic Electromagnetlc Flelds, (McGraw-Hi11, New York, 1961).

4. Lorrain, Paul and Carson, Dale, Electromagnetic Flelds and Waves, (W. H. Freeman \& Co., New York, 1970).

5. Kraus, John, Electro-Magnetics, (McGraw-Hi11, New York, 1952).

6. Mitra, R. and Lee, S. W., Analytical Techniques in the Theory of Guided Waves, (Macmillan, New York, 1971). 
Internal:

C. Baker

M. Billone

J. Brooks

Y. Cha

O. Chopra

R. Clemmer

D. Ehst

R. Evans

P. Finn

Y. Gohar

L. Greenwood
D. Gruen

A. Has sanein

T. Hua

C. Johnson

A. Krauss

Y. Liu

B. Loomis

S. Majundar

R. Mattas

B. Picologlou

K. Porges
C. Reed

D. Smith

H. Stevens

D. Sze

L. Turner

T. Yule

FPP Eiles (15)

ANL Contract File

ANL Libraries

ANL Patent bept. TIS Files (5)

\section{External:}

DOE-TIC, for distribution per UC-20 (103)

Manager, Chicago Operations of fice

S. Berk, Office of Fusion Energy

M. Cohen, Office of Fusion Energy

R. Dowling, Office of Fusion Energy

G. Hass, Office of Fusion Energy

G. R. Nardella, Office of Fusion Energy

A. Opdenaker, Office of Fusion Energy

T. Reuther, office of Fusion Energy

P. Stone, Office of Fusion Energy

S. Abdel-Khalik, University of Wisconsin

M. Abdou, University of California, Los Angeles

J. Anderson, Los Alamos Nationa? Laboratory

S. Baron, Brookhaven National Laboratory

H. Bauer, Sandia Laboratories

L. Bromberg, Massachusetts Institute of Technology

D. Cohn, Massachusetts Institute of Technology

R. Conn, University of California, Los Angeles

J. Crocker, EGEG Idaho, Inc.

J. Davis, McDonnel1 Douglas Astronautics Coinany

S. Dean, Fusion Power As sociates

T. Drolet, Ontario Hydro, CANADA

C. Flanagan, Fusion Engineering Design Center/Oak Ridge National Laboratory

H. Forsen, Bechtel National, Inc.

H. Furth, Princeton Plasma Physics Laboratory

J. Garner, TRW, Inc.

N. Ghoneim, University of California, Los Angeles

P. Gierszewsiki, Canadian Fusion Fuels Technology Project

J. Gordon, TRW, Inc.

R. A. Gross, Columbia University

R. Hancox, Culham Laboratory

C. Henning, Lawrence Livermore National Laboratory

N. Hoffman, Energy Technology Engineering Center

G. Hollenberg, Hanford Engineering Development Laboratory

M. Razimi, Massachusetts Institute of Technology 


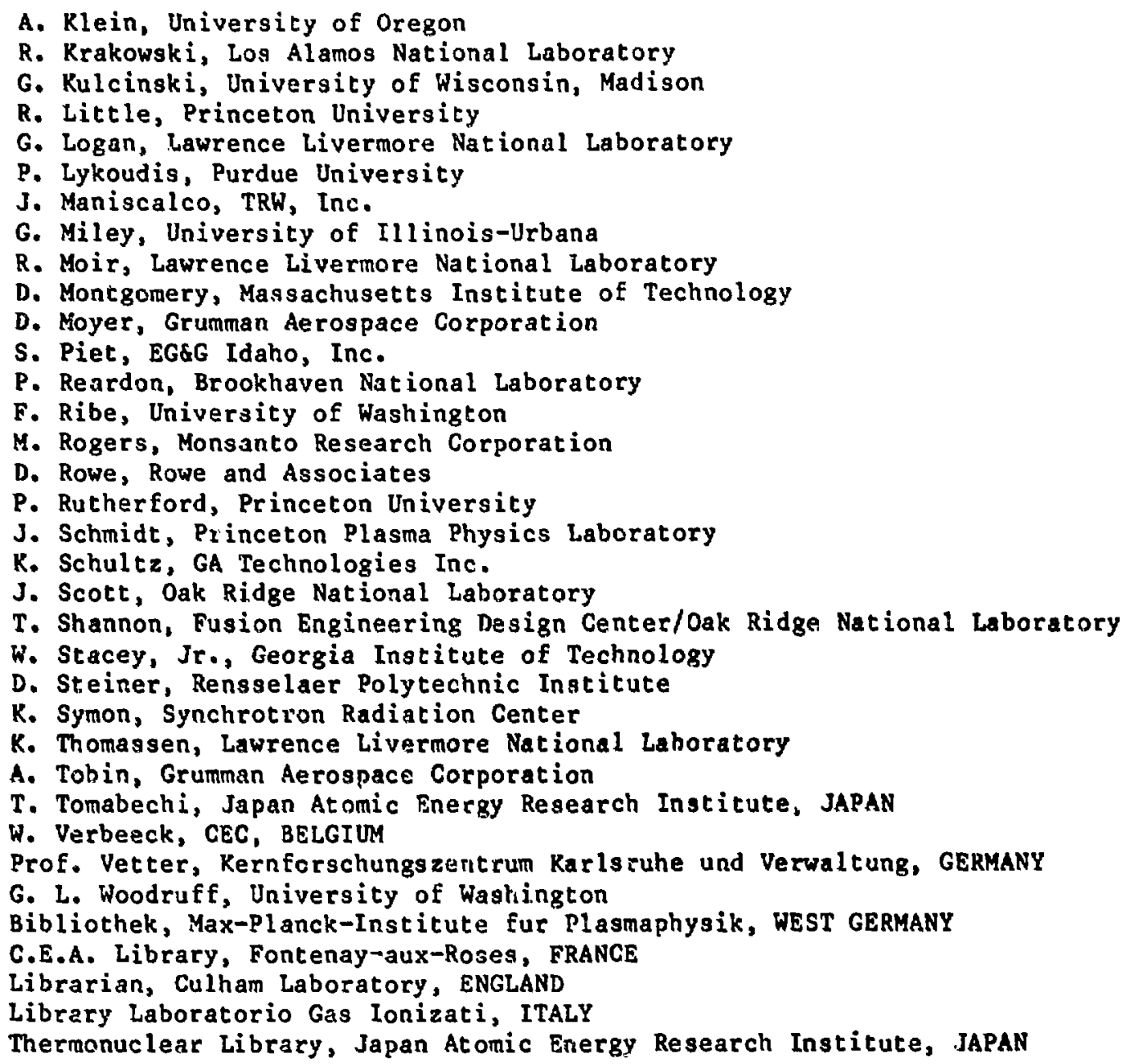

